\title{
Hematopoietic potential of mouse placenta with the application of placenta flushing
}

\author{
BIN WEI ${ }^{1}$, SUOMAO YUAN $^{2}$, YINGMAO GAO $^{1, *}$ and LUJUN BING ${ }^{1}$
}

\author{
${ }^{1}$ Histology and Embryology Institute, Medical School of Shandong University, Jinan, Shandong, 250012, PR \\ China \\ ${ }^{2}$ Peking Union Medical College Hospital, Chinese Academy of Medical Science \& Peking Union Medical \\ College, Beijing, 100730, PR China
}

\begin{abstract}
Several major vascular tissues, such as the aorta-gonad-mesonephros region (AGM), yolk sac, and fetal liver have been confirmed to possess hematopoietic function. Recently, the placenta has been demonstrated as another hematopoietic organ. However, it is not conclusive whether the placenta possesses hematopoietic ability. Therefore, we undertook a series of experiments to study the hematopoietic functions of placenta. Fetal blood circulation in the placenta is difficult to be eliminated and its interference in the study of placental hematopoiesis is inevitable. With the application of placental flushing, fetal blood contained in the placenta was eliminated. We then made the further study of placental hematopoiesis after the E12.5 placenta was flushed. Our studies showed that placental cells expressing Sca-1, CD117 and CD34 were mainly restricted to the embryonic vessels of E12.5 placenta. The results of fluorescence activated cell sorter (FACs) analysis and colony forming cells (CFC) assay demonstrated that both placenta and placental blood contained hematopoietic stem/progenitor cells (HS/PCs), including CFU-GMs, CFU-GEMMs, BFU-Es, and HPP-CFCs. The frequency of HS/PCs in the placenta was 2-3 times that of placental blood. Therefore, it is necessary to clear placental blood out of the placenta in the studies of the hematopoietic potential of placenta. The placenta still possessed the hematopoietic potential after the fetal blood is flushed out. These observations provide further evidences that the placenta is a hematopoietic organ, as has been proposed for other embryonic hematopoietic sites.
\end{abstract}

Key terms: placenta, hematopoiesis, HS/PCs, mouse

\section{INTRODUCTION}

The ontogeny of the hematopoietic system in vertebrates is characterized by sequential activity of distinct hematopoietic organs. Coordinated activities of the different hematopoietic sites ensure both rapid production of differentiated blood cells for the embryo's immediate needs and the establishment of a large pool of undifferentiated hematopoietic stem cells (HSCs). Yolk sac, fetal liver, thymus, spleen and bone marrow have been identified as the organs carrying out this function in mammalian embryos.

Recently, a series of studies have suggested that the fetal placenta is also a hematopoietic organ that plays an important role in establishing the HSC pool during development. The study by Alvarez-Silva and colleagues shows that the placenta contains a high frequency of multi-potential colonogenic progenitors, before liver colonization initiates (Alvarez-Silva et al., 2003). Furthermore, subsequent in vivo studies show that midgestation placenta also harbors a large pool of pluripotent HSCs that have the capacity to self-renew and repopulate the entire hematopoietic system in irradiated adult hosts (Gekas et al., 2005; Ottersbach and Dzierzak, 2005). These studies have established the placenta as yet another hematopoietic organ that plays an

\footnotetext{
* Corresponding author: Yingmao Gao, Wenhua West Road 44\#, Jinan, Shandong, PR China. Telephone +86 (0)531 88380491.E-mail address:yingmaogao@hotmail.com.
} 
important role in HSC development. However, the aforementioned studies do not give clues to whether the placenta is simply a colonization site (like the fetal liver), or whether it is also a source of hematopoietic cells. The studies of Zeigler et al (2006) and Corbin et al (2007) demonstrated that the two precursors of the placenta, the allantois and the chorion, possessed hematopoietic potential before their fusion into placenta. Thus, it seems the placenta maintains its hematopoietic potential from its formation to the midgestation. However, previous studies have shown that the vasculature system of the placenta is established several days after the formation of placenta, and that umbilical blood contained a high percentage of HS/PCs. These facts make it unclear whether the hematopoietic potential of the midgestation placenta was from placental cells, or from fetal blood, or from both. Consequently, we developed the technique of placenta flushing to clear fetal blood cells in the placenta before making further study of placental hematopoiesis.

\section{MATERIALS AND METHODS}

\section{Mice}

C57BL/6 mice were mated overnight, and the day of vaginal plug was considered as day 0.5 of embryonic development (E0.5). The animals were housed according to institutional guidelines, with free access to food and water. Animal procedures were carried out in compliance with the Standards for Humane Care and Use of Laboratory Animals.

\section{Placental flushing}

Pregnant females of E12.5 were killed by cervical dislocation. The uterine was removed from the conceptuses, washed extensively in D-Hank's balanced salt solution. The uterine was opened and embryos at E12.5 were harvested. The entirety of embryo, umbilical cord and placenta was maintained intact. Placenta flushing was performed immediately after the embryos were removed from the uterine. Under a stereomicroscope (Olympos, JPN), the umbilical artery and vein were identified by the direction of blood flow. A fine needle (BD29 G) was inserted into the umbilical artery with the tip pointing to the placenta. Heparin saline (concentration $0.5 \mathrm{mg} / \mathrm{ml}, 290000 \mathrm{IU} / \mathrm{ml}$ ) was used as flushing fluid and injected into the umbilical artery slowly $(0.1 \mathrm{ml} / \mathrm{min})$ to flush the embryonic vessel system of the placenta. The flushed blood from the placenta was collected for the further assay. To quantify and determine the flushing effect, thirty placentas were collected and divided into six groups at random. In the six groups, the volumes of flushing fluid used were $0 \mathrm{ml}, 0.05 \mathrm{ml}, 0.10 \mathrm{ml}, 0.15 \mathrm{ml}$, $0.20 \mathrm{ml}$, and $0.25 \mathrm{ml}$, respectively. Then the placentas were serially cryosectioned coronally at $10 \mu \mathrm{m}$. One slice in every ten serial slices was collected and total 20 slices for each placenta were harvested to evaluate the flushing effect. After hematoxylin-eosin staining, ten visual fields $(\times 400)$ were selected randomly for each slice. Then the fetal blood cells in the embryonic vessels were counted in each visual field and the data were recorded for statistical analysis with the one-way ANOVA, using the SPSS software package (SPSS, USA).

\section{Placentas dissection, immunofluorescence, and confocal microscopy}

Placentas of E12.5 were dissected from maternal tissue. Frozen sections $(10 \mu \mathrm{m})$ were collected on plus slides and were fixed by acetone. Slides were then stored at $4{ }^{\circ} \mathrm{C}$, until ready for use. The sections were incubated with rat monoclonal anti-mouse CD34 (Serotec, UK), CD117 (Biolegend, USA), and Sca-1 (Biolegend, USA) for 1 hour at $37{ }^{\circ} \mathrm{C}$. The sections were incubated for a further hour at room temperature in fluoresceinisothiocyanate (FITC)-labeled goat anti-rat IgG (KPL, UK). A negative isotype matched control was prepared by replacing the CD34 primary antibody with PBS with the same concentrations as those of the primary antibodies. A positive 
control section of mouse fetal liver was included in each batch of staining.

\section{Single cell suspension preparations and} density gradient centrifugation

To functionally assess hematopoietic activity of the flushed placenta, the placentas (free of umbilical cord, remnants of the yolk sac and maternal decidua) were dissected and dissociated into single cell suspension. The placentas were mechanically dissected free and drawn through a $16 \mathrm{G}$ needle and incubated with $0.1 \%$ collagenase in $10 \%$ fetal calf serum (FCS) / phosphate-buffered saline (PBS) for 30 minutes at $37^{\circ} \mathrm{C}$ and trypsin for 10 minutes at $37^{\circ} \mathrm{C}$. Then the Percoll (Amersham, UK) fluids of different density $(1.10 / \mathrm{ml}, 1.080 \mathrm{~g} / \mathrm{ml}, 1.055 \mathrm{~g} / \mathrm{ml})$ were added into the centrifuge tube one by one from higher density to less, and then the cell suspension was gently placed at the utmost upper layer. After centrifugation for 25 minutes with $2000 \mathrm{rpm}$, the cells residing between the top layer and the middle layer were harvested. The purified single cell suspension was counted and viability was tested via Trypan blue exclusion criteria. Meanwhile, the flushed blood cells from the placenta were prepared and treated according to this procedure.

Fluorescent antibody surface staining and flow cytometry

All antibody stainings were carried out in a volume of $100-200 \mu \mathrm{lBS} / 10 \%$ FCS on ice for 30 minutes with the following antibodies (Biolegend, USA): anti-CD34PE, anti-CD117-PE, and anti-Sca-1-FITC. Labeled cells were finally washed twice in PBS, and filtered through a nylon mesh screen to remove debris. The cells were analyzed using a flow cytometry (Beckman Coulter, USA). The data were analyzed using the System II version 3.0. Each value was obtained from the means of six independent experiments. To determine background levels, cells were stained with fluorochrome-conjugated immunoglobulin isotype controls from Biolegend.
Clone forming cells (CFC) and high proliferation-potential colony-forming cells (HPP-CFC) assays

For analysis of progenitor activity in the E12.5 flushed placenta, $10^{5}$ purified single cells were plated per $35 \mathrm{~mm}$ dish in MethoCult M3434 methylcellulose media (Stem Cell Technologies, CAN). The commercial medium contains methylcellulose in IMDM [15\% fetal calf serum (FCS), 1\% bovine serum albumin (BSA), $10^{-4}$ M 2-mercaptoethanol, $2 \mathrm{mM}$ glutamine, $3 \mathrm{U} / \mathrm{ml}$ recombinant human (rh) erythropoietin, $10 \mathrm{ng} / \mathrm{ml} \mathrm{rh}$ interleukin 6 (IL-6), $10 \mathrm{ng} / \mathrm{ml}$ recombinant mouse (rm) IL-3, $50 \mathrm{ng} / \mathrm{ml} \mathrm{rm} \mathrm{Stem} \mathrm{Cell} \mathrm{Factor} \mathrm{(SCF),}$ $10 \mathrm{mg} / \mathrm{ml} \mathrm{rh}$ insulin and $200 \mathrm{mg} / \mathrm{ml}$ human transferrin (iron saturated)]. After 14 days of culture at $37^{\circ} \mathrm{C}$ in a humid atmosphere containing $5 \% \quad \mathrm{CO}_{2}$, colonies were identified based on their morphology under an inverted microscope and scored. Each value was obtained from the means of six independent assays.

To check for the presence of long-term HPP-CFCs, first passage colonies with a diameter exceeding $0.5 \mathrm{~mm}$ were plucked after 20-25 days of culture, pooled and washed with PBS. Cells were counted and $10^{5}$ cells were replated per dish in MethoCult M3434 medium. The colonies were replated three times according to the same protocol and scored 60 days after initial seeding.

\section{RESULTS}

\section{The effect of placenta flushing}

The unflushed placenta was full of fetal circulation blood. After flushing, fetal circulation blood was cleared out of the placenta (Fig 1A). Under microscope, we found fetal blood cells that were previously trapped in the embryonic vessels (Fig 1B) had been completely flushed out of the placenta, and placenta flushing caused no expansion of the vessel lumina. The structure of endothelial cells of the embryonic vessels and other cells still remained intact and the tissue space was 
normal (Fig 1C). The relationship between the flushing volume and the flushing effect is shown in Fig 1D. The results of statistical analysis demonstrated that the differences between the first five groups $(0 \mathrm{ml}, 0.05 \mathrm{ml}$, $0.10 \mathrm{ml}, 0.15 \mathrm{ml}$, and $0.20 \mathrm{ml}$ ) were significant $(\mathrm{P}<0.05)$, while the difference between the last two groups $(0.20 \mathrm{ml}$ and $0.25 \mathrm{ml})$ was not statistically significant $(\mathrm{P}>0.05)$. In our subsequent experiments, we flushed each placenta with $0.2 \mathrm{ml}$ flushing fluid.

\section{Phenotype and localization of placental HS/ PCs}

At E12.5, CD34 stained the endothelial cells lining the vessels in the placenta labyrinth (Fig 2A). CD $117^{+}$cells were mainly found in the endothelial cells lining the vessels in the placenta labyrinth and the mesenchymal tissue of the chorionic plate and the labyrinth (Fig 2B). Most strikingly, a high level of Sca-1 expression was found in the embryonic vessels of the placenta (Fig 2C and D). Sca-1 expression was in the endothelial cells lining the fetal vessels that formed a network through the labyrinth region. It was also expressed by a few endothelial cells lining the vessels in the chorionic plate. At E12.5, in the endothelial cells of the umbilical artery, the expression of CD34 and Sca-1 could also be detected (Fig 1E and F), while the expression of CD117 could not be detected.

The number and phenotypic analysis of the isolated and purified cells in the placenta and placental blood

First, we isolated and purified the placental cells with Percoll fluid. We then performed flow cytometric analysis to determine the number and phenotypic characteristics of the purified placental cells in the placenta and placental blood. Placental cells were stained with antibodies specific for $\mathrm{HS} / \mathrm{PC}$ markers: Sca-1(HSC marker), CD34 (endothelial and HSC marker), and CD117 (HSC and immature, hematopoietic progenitor marker). The percentages of the three cell populations in the total purified placental cells were $20.2 \%, 24.6 \%$, and $26.2 \%$ respectively. For purified placental blood cells, the percentages of the three populations were $8.2 \%, 6.3 \%$, and $6.5 \%$, respectively. The concentration of positive cells in placental cells was higher than in placental blood. The absolute numbers of positive cells of CD34, CD117 and Sca-1
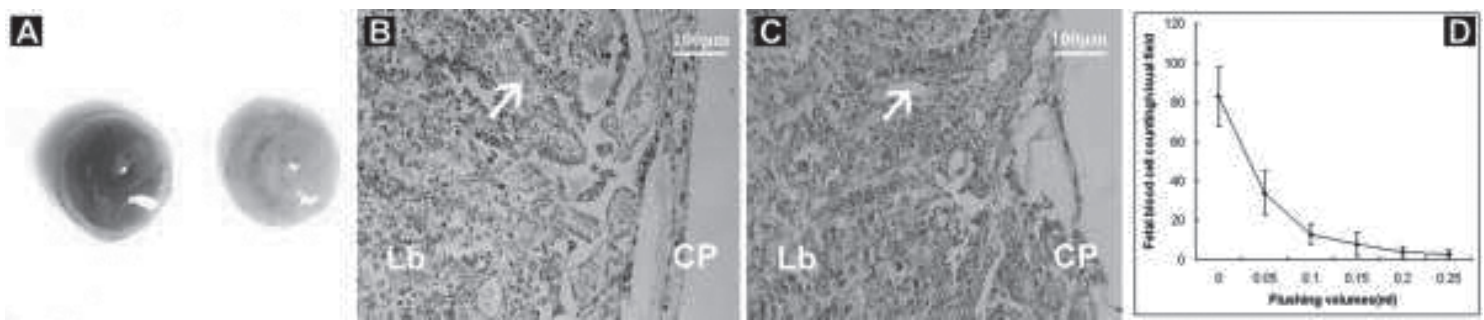

Fig. 1: Unflushed and flushed placentas. (A)The left placenta was full of fetal blood before flushing. The right is a flushed placenta. The upper layer was the fetal part. (B) In the section of E12.5 unflushed placenta, hematoxylin-eosin staining showed many vessels surrounded by a thin endothelial layer, which were the embryonic/fetal vessels in the placental labyrinth. The lumen of many vessels of the embryonic vessels in the placental labyrinth was filled with packed erythroblasts. (C) In the section of the flushed placenta, there were no blood cells left in the lumen of blood vessels of the embryonic vessels in the placental labyrinth. White arrows show the lumen of the embryonic vessels in the placental labyrinth. (D) The relationship between the flushing volume and the flushing effect. The cell number in the fetal blood vessels/visual field was the average of the total visual fields of the five placentas in each group. For each placenta, 200 visual fields were counted. The flushing speed was $0.1 \mathrm{ml} / \mathrm{min}$. Chorionic plate $(\mathrm{CP})$, placenta labyrinth (Lb). 
were $1.4 \times 10^{4}, 1.8 \times 10^{4}$, and $1.8 \times 10^{4}$ respectively in purified placental cells, and were $0.7 \times 10^{4} \quad 0.5 \times 10^{4}$, and $0.5 \times 10^{4}$ respectively in purified placental blood (Table 1). The number of positive cells in the purified placental cells was higher than in purified placental blood. For the cell subpopulation of $\mathrm{CD}_{3} 4^{+} / \mathrm{Sca}-1^{+}$, the percentage in purified placental cell $(15.3 \%)$ was also higher than in placental blood $(5.1 \%)$. In placental cells, $58 \%$ of Sca- $1^{+}$cells expressed CD34. In placental blood, $78 \%$ of Sca- $1^{+}$cells expressed CD34 (Fig 3).

\section{Frequency of short-term progenitors}

These experiments were carried out using E12.5, isolated and purified cell preparations. Three different types of progenitors - CFUGEMMs (colony forming units, granulocytes, erythrocytes, monocytes, macrophages), BFU-Es (burst-forming units, erythroid) and CFU-GMs (colony-forming units, granulocytes, macrophages) - diagnosed from the colony phenotype, were scored separately on day 14 of culture (Fig. 4). CFU-GEMMs exceeding $0.5 \mathrm{~mm}$ in diameter (HPP-CFCs) were selected for serial replating.
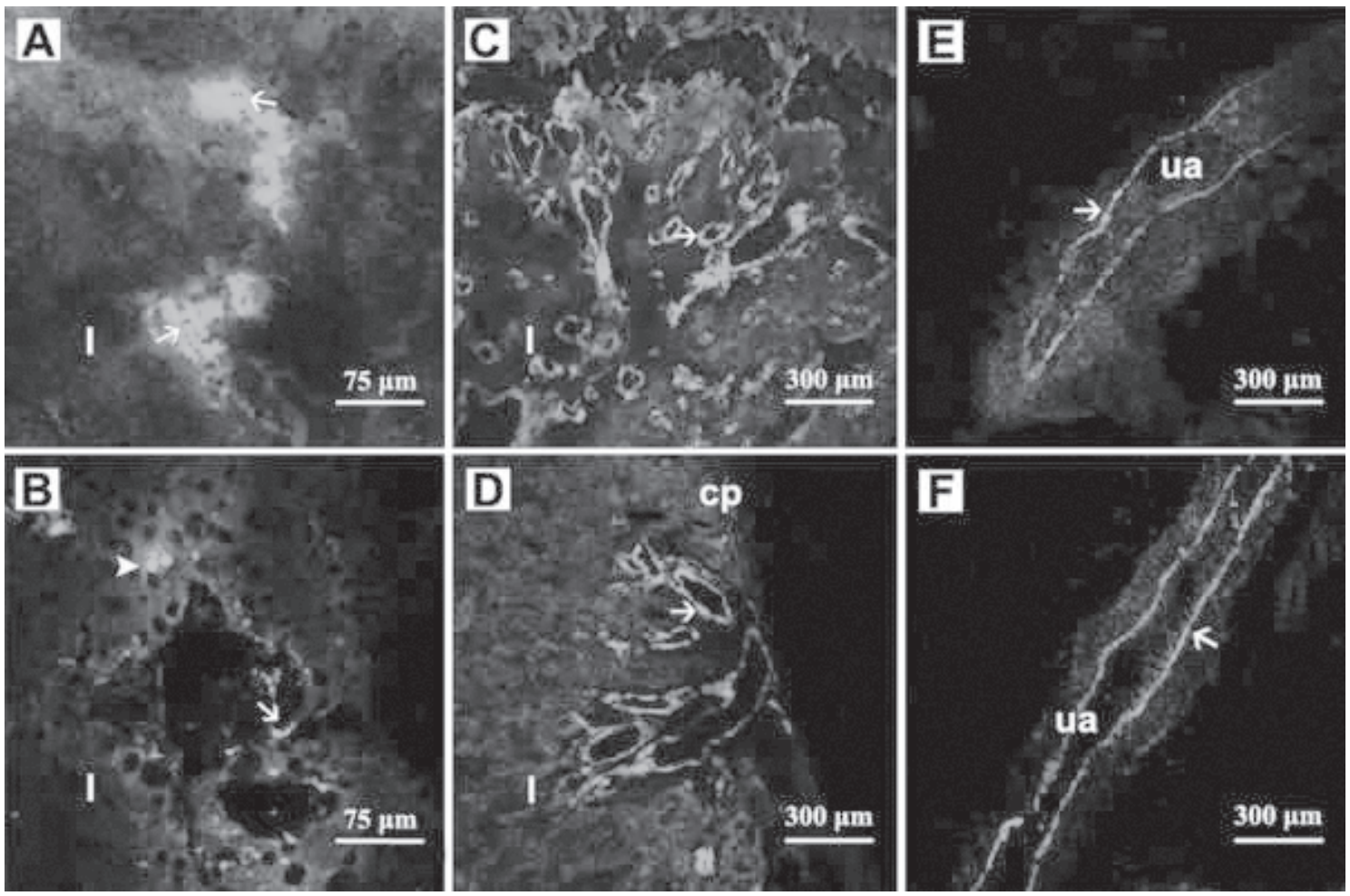

Fig. 2: Expression of CD34, CD117, and Sca-1 in the placenta and umbilical artery. (A) Coronal section of E12.5 placenta was stained with antibodies against CD34. Arrows indicate the endothelial cells of embryonic vessels. (B) Coronal section of E12.5 placenta was stained with antibodies against CD117. Arrow shows the endothelial cells of embryonic vessels. Arrowhead indicates the mesenchymal cells of the placenta labyrinth. (C) Coronal section of E12.5 placenta was stained with antibodies against Sca-1. Arrow indicates the endothelial cells of embryonic vessels. (D) Transverse section of E12.5 placenta was stained with antibodies against Sca-1. Arrow shows the endothelial cells of embryonic vessels. (E) Longitudinal section of E12.5 umbilical vessels stained with anti-CD34 antibody. Arrow indicates the endothelial cells of umbilical artery. (F) Longitudinal section of E12.5 umbilical vessels stained with anti-Sca-1 antibody. Arrow shows the endothelial cells of umbilical artery. (A-F) Sections were analyzed by confocal microscopy. cp, chorionic plate; 1, labyrinth; ua, umbilical artery. 


\section{TABLE 1}

The cell number of single cell suspension, isolated and purified cells and FACS assay in flushed placenta and placental blood at E12.5.

\begin{tabular}{|c|c|c|c|c|}
\hline & \multicolumn{2}{|c|}{ Examined tissues } & Absolute number $(x \pm s)$ & $\operatorname{Percentage}(x \pm s \%)$ \\
\hline $\begin{array}{l}\text { Total cell number of single } \\
\text { cell suspension } / \mathrm{PL}\end{array}$ & $\begin{array}{l}\text { Flushed PL } \\
\text { PB }\end{array}$ & & $\begin{array}{l}6.2 \pm 0.4 \times 10^{7} \\
3.3 \pm 0.3 \times 10^{7}\end{array}$ & - \\
\hline $\begin{array}{l}\text { Number of isolated and } \\
\text { purified cells /PL }\end{array}$ & $\begin{array}{l}\text { Flushed PL } \\
\text { PB }\end{array}$ & & $\begin{array}{l}0.7 \pm 0.2 \times 10^{5} \\
0.7 \pm 0.5 \times 10^{5}\end{array}$ & - \\
\hline FACS assay & Flushed PL & $\begin{array}{c}\text { CD34+ } \\
\text { CD117+ } \\
\text { Sca-1+ } \\
\text { CD34+/Sca-1+ } \\
\text { CD34+ } \\
\text { CD117+ } \\
\text { Sca-1+ } \\
\text { CD34+/Sca-1+ }\end{array}$ & $\begin{array}{l}1.4 \times 10^{4} \\
1.8 \times 10^{4} \\
1.8 \times 10^{4} \\
1.1 \times 10^{4} \\
0.6 \times 10^{4} \\
0.5 \times 10^{4} \\
0.5 \times 10^{4} \\
0.4 \times 10^{4}\end{array}$ & $\begin{array}{l}20.2 \pm 3.0 \\
24.6 \pm 6.2 \\
26.2 \pm 5.2 \\
15.3 \pm 4.1 \\
8.2 \pm 3.5 \\
6.3 \pm 2.8 \\
6.5 \pm 3.3 \\
5.1 \pm 3.1\end{array}$ \\
\hline
\end{tabular}

PL: placenta; PB: placental blood.

\section{Placenta}

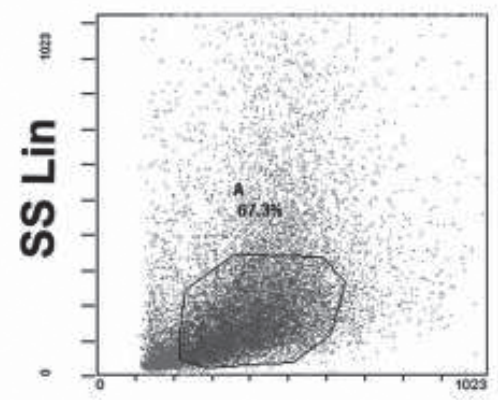

FS Lin

\section{Blood}

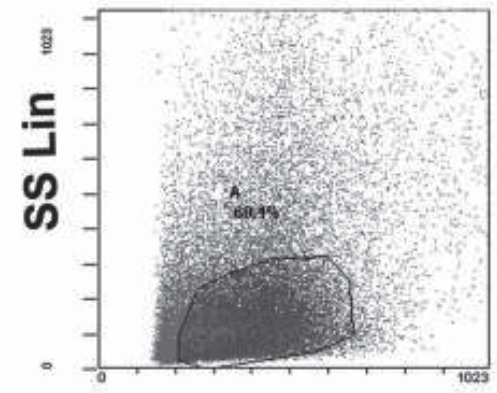

FS Lin

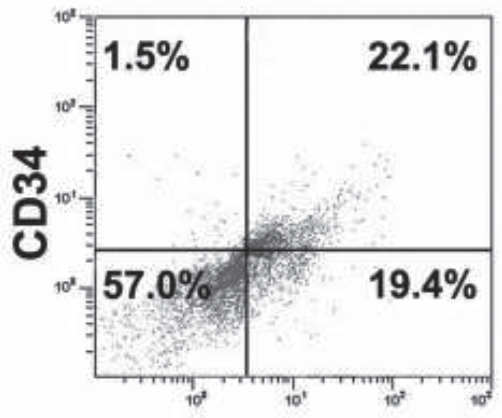

Sca-1

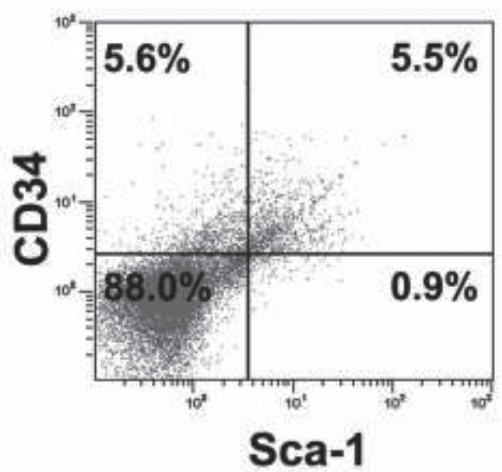

Fig. 3: Flow cytometric analysis of E12.5 placenta and placental blood. Isolated and purified cells from E12.5 placenta and placental blood were stained with phycoerythrin-conjugated antibodies against CD34 as indicated on the y axis and FITC- conjugated antibodies against Sca-1 as indicated on the $\mathrm{x}$ axis. Percentages for each population are indicated inside the quadrants. 

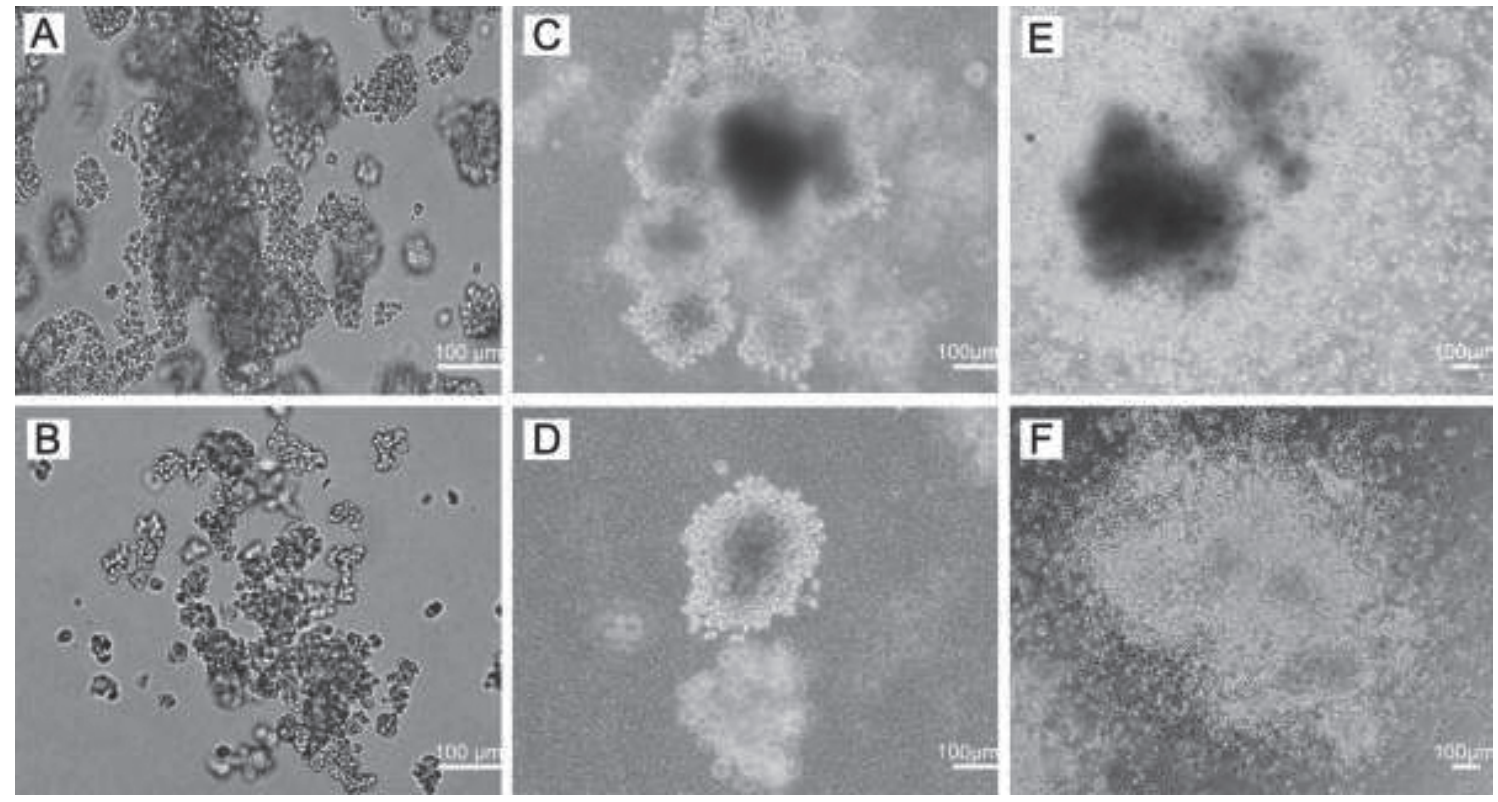

Fig. 4: CFU-GEMM, BFU-E, CFU-GM colonies obtained from E12.5 placenta and placental blood after 14 days of culture in methylcellulose-based medium. (A) Placental BFU-E colonies were multicentered and highly hemoglobinized. (B) Placental blood BFU-Es displayed only weakly hemoglobinized clusters. (C) Placental CFU-GM colonies were dense, medium to large sized, and often actually so large that they seemed to result from the fusion of clusters. (D) Placental blood CFU-GMs were small-sized. (E) Placenta CFU-GEMM colonies were characterized by large diameter exceeding $0.5 \mathrm{~mm}$, with a very large core of hemoglobinized cells. (F) Placental blood CFU-GEMMs were less hemoglobinized.

After culturing for 14 days, the colony yields of BFU-Es, CFU-GMs, and CFUGEMMs in placental cells were higher than in placental blood. The frequency of placental BFU-Es was at least two times higher than that of placental blood BFU-Es. The frequency of CFU-GEMMs in the placenta was also two times as high as in the placental blood. Nevertheless, the frequency of the placental CFU-GMs was only one time higher than that of the placental blood CFU-GMs. The characteristics of the morphology of placental BFU-Es was multicentered and highly hemoglobinized, while placental blood BFU-Es displayed only weakly hemoglobinized clusters (Fig. 4A, B). In the case of CFU-GMs, placental CFU-GMs were dense, medium to large sized, and often actually so large that they seemed to result from the fusion of clusters, whereas placental blood CFU-GMs were small sized(Fig. 4C, D). Both placental CFU-GEMMs and placental blood CFU-
GEMMs were huge, and so qualified more adequately as HPP-CFCs. Compared to placental blood CFU-GEMMs, placental CFU-GEMMs appeared larger, denser, and contained more cells, with a very large core of hemoglobinized cells (Fig. 4E, F).

\section{Long-term HPP-CFCs}

In order to monitor the self-renewal capacity of hematopoietic progenitors in the placenta and placental blood, we replated the very large multilineage colonies derived from HPP-CFCs every 2 weeks for 2-3 months. At each replating, some very large colonies were again obtained. When the colonies were scored at 60 days, 35 CFU-GEMMs can be obtained from $10^{5}$ replated placental cells. By contrast, HPP-CFCs could also be obtained from the placental blood and the frequency was about two-thirds of the placenta (Fig 5). Furthermore, the placental blood colonies were smaller than the placental colonies. 


\section{Frequency of short-term progenitors and long-term HPP-CFCs in placenta and placental blood}

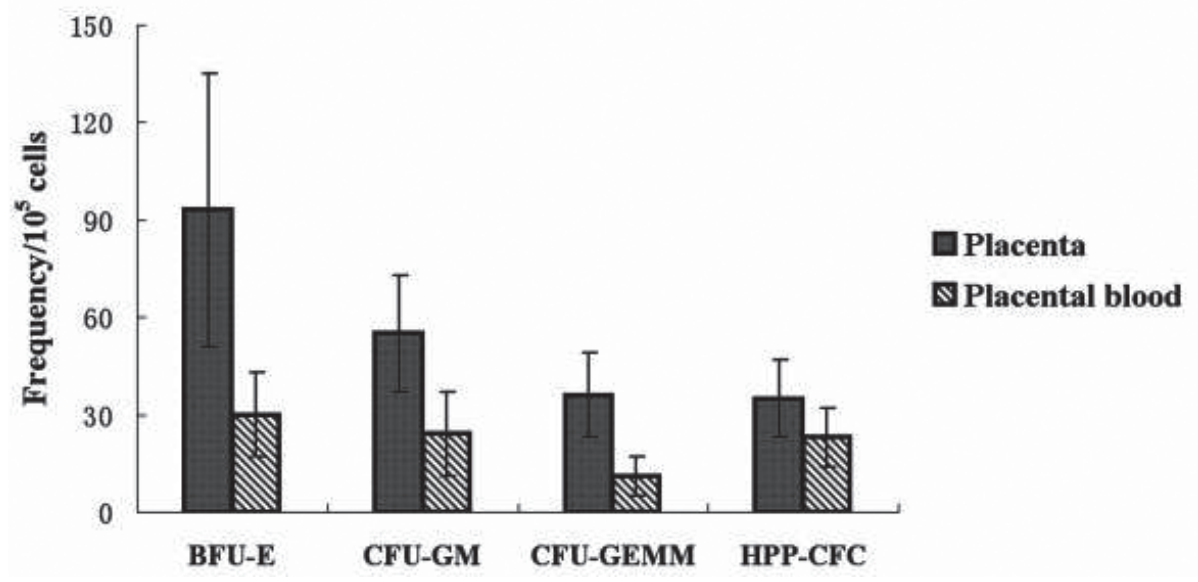

Fig. 5: Short-term progenitors assay and long-term HPP-CFCs assay. $10^{5}$ isolated and purified cells were used for short-term progenitors assay in both placenta and placental blood. After 14 days of culture, colonies were identified based on their morphology and scored. HPP-CFCs were taken from MethoCult M3434 cultures every 20-25days. $10^{5}$ cells from pooled colonies were replated at each passage. HPP-CFCs were scored after a total 60 days in culture. Each result is the mean \pm s.d. from six independent experiments.

\section{DISCUSSION}

Proper function of the placenta is essential for the development of the growing embryo. In previous studies, the placenta has not been regarded as taking part in fetal blood formation. Recently, a series of studies suggest that the fetal placenta is also a hematopoietic organ that plays an important role in establishing the HSCs pool during development. Alvarez-Silva et al (2003) examined the progenitors in E8E17 placenta and found that the progenitors began to appear at the stage of $18 \mathrm{sp}$ (E8.5) in the placenta. To examine the placenta for potent, adult-engrafting HSCs, Ottersbach and Dzierzak (2005) examined E9-E12 placenta (without the decidua or umbilical vessels). It was shown that no HSCs were found in E9 or E10 placenta. However, potent placental HSCs began to be detected at E11 and were present at high levels at E12.

As is known, the placenta labyrinth contains abundant fetal circulation blood. From E10.0 the definitive hematopoietic progenitors prefer to begin to freely distribute within the embryonic vasculature (McGrath et al., 2003). Long-term reconstituting $\mathrm{HSCs}$ appears in circulation by E12.5 (Christensen et al., 2004). Kumaravelu et al. (2002) found that at E12 there are $3.2 \mathrm{HSCs}$ in circulation. In our study, we performed short-term progenitor assay and FACs with the flushed placental blood. The results showed the blood trapped in the E12.5 placenta contained a quantity of progenitors, which was about 1/ 3-1/2 of that in E12.5 placenta. Therefore, fetal blood cells trapped in the placenta should be one of the important factors to be considered in the study of placental hematopoiesis. However, how to clear fetal circulation blood in the placenta and detect the function of placental HS/PCs is still a problem. Consequently, we developed the technique of placenta flushing. In our result, there was no significant difference in flushing effect between $0.2 \mathrm{ml}$ group and $0.25 \mathrm{ml}$ group. It seemed that more flushing fluid than $0.20 \mathrm{ml}$ could not bring more fetal blood cells out. But remnant fetal blood cells in the placenta were not more than $2 \%$, and the fetal blood could be nearly 
cleared out of the placenta with $0.2 \mathrm{ml}$ flushing fluid.

First, we observed the distribution of $\mathrm{HS} / \mathrm{PCs}$ in the mouse placenta using the HSC surface markers. By immunohistochemical analysis, it was shown that high-level Sca-1 expression was restricted to the embryonic vessels of the placental labyrinth. Moreover, other HSC markers also were colocalized in the embryonic vessels of the placental labyrinth region. Furthermore, we performed immunohistochemical analysis of umbilical cord with the same HSC surface markers. It was found that the HS/PCs were also restricted to the endothelium of the umbilical artery.

To examine hematopoietic activity, it is essential to first isolate placental cells with hematopoietic function. Continuous enzymatic digestion with collagenase and pancreatin was used to prepare placental cell suspension. To obtain highly concentrated placental HS/PCs, the single cell suspension was isolated and purified with Percoll fluid density gradient separation. After purification, the concentration of $\mathrm{Sca}_{-1}{ }^{+}$cells could be raised to $26.2 \%$ at E12.5, while Sca- $1^{+}$cells represented only $3.09 \%$ of the unpurified total cell population at E12 in Ottersbach and Dzierzaks' report (Ottersbach and Dzierzak, 2005). Therefore, Percoll density gradient centrifugation method could be used to isolate and purify placental HS/PCs. The further analysis of the hematopoietic potential of the purified placental cells showed that the placenta of midgestation contained clonogenic hematopoietic progenitors, including CFU-GMs, CFUGEMMs, BFU-Es, and HPP-CFCs.

The murine allantois contributes the fetal vascular and associated stromal components of the placenta, including the umbilical vessels (Downs et al., 1998). At E8.5, the murine allantois makes contact with the chorion (Cross, 1998; Cross et al., 2003a, 2003b; Han and Carter, 2001; Rossant and Cross, 2001). The allantois has been identified as a third site of hematopoiesis in the chick embryo (Caprioli et al., 1998). However, in murine embryos, it is not yet clear whether the allantois is hematopoietic (Downs and Harmann, 1997). Brandon M. Zeigler et al. (2006) investigated the hematopoietic potential of the two individual components of the murine placenta, the allantois and the chorion, prior to establishment of vascular continuity within the conceptus. Their studies demonstrated that the allantois and chorion, isolated prior to the establishment of circulation, have the potential to give rise to myeloid and definitive erythroid cells following explant culture. Catherine Corbel et al. (2007) examined the hematopoietic potential of the prefusion allantois and provided evidence that the allantois has hematopoietic potential per se. Since the embryonic vessels of the placenta were derived from the allantois, and the hematopoietic potential of midgestation placenta was mainly restricted to the embryonic vessels of the placental labyrinth, it may be reasonable to infer that the hematopoietic potential of the midgesation placenta was the continuity of the hematopoietic potential of allantois.

In conclusion, both placenta and placental blood contain a quantity of HS/ $\mathrm{PCs}$ in the midgestation placenta. It is necessary to clear the placental blood out of the placenta in studies of the hematopoietic potential of the placenta. The midgestation placenta still possesses hematopoietia potential after the fetal blood is flushed out.

\section{ACKNOWLEDGMENTS}

We thank the members of the laboratory for assistance in various parts of these studies and for stimulating discussions, and Faliang Zhu for assistance with multicolor flow cytometry. We especially acknowledge the excellent assistance with microscopy provided by Dr. Yuji Guo. All other authors remain free from any conflicts of interest.

\section{REFERENCES}

ÁLVAREZ-SILVA M, BELO-DIABANGOUAYA P, SALAÜN J, DIETERLEN-LIÈVRE F (2003) Mouse placenta is a major hematopoietic organ. Development, 130: $5437-5444$

CAPRIOLI A, JAFFREDO T, GAUTIER R, DUBOURG C, 
DIETERLEN-LIEVRE F (1998) Blood-borne seeding by hematopoietic and endothelial precursors from the allantois. Proc Natl Acad Sci U S A, 95: 1641-1646

CHRISTENSEN JL, WRIGHT DE, WAGERS AJ, WEISSMAN IL (2004) Circulation and chemotaxis of fetal hematopoietic stem cells. PLoS Biol, 2: E75

CORBEL C, SALAUN J, BELO-DIABANGOUAYA P, DIETERLEN-LIEVRE F (2007) Hematopoietic potential of the pre-fusion allantois. Dev Biol, 301: 478-488

CROSS JC (1998) Formation of the placenta and extraembryonic membranes. Ann N Y Acad Sci, 857:23-32

CROSS JC, BACZYK D, DOBRIC N, HEMBERGER M, HUGHES M, SIMMONS DG, YAMAMOTO $\mathrm{H}$, KINGDOM JC (2003) Genes, development and evolution of the placenta. Placenta, 24:123-130

CROSS JC, SIMMONS DG, WATSON ED (2003) Chorioallantoic morphogenesis and formation of the placental villous tree. Ann.N Y Acad. Sci, 995: 84-93

DOWNS KM, HARMANN C (1997) Developmental potency of the murine allantois. Development, 124: $2769-2780$

DOWNS KM, GIFFORD S, BLAHNIK M, GARDNER RL (1998) Vascularization in the murine allantois occurs by vasculogenesis with out accompanying erythropoiesis. Development, 125: 4507-4520

GEKAS C, DIETERLEN-LIEVRE F, ORKIN SH,
MIKKOLA HK (2005) The placenta is a niche for hematopoietic stem cells. Dev Cell, 8:365-375

HAN VK, CARTER AM (2001) Control of growth and development of the feto-placental unit. Curr Opin Pharmacol, 1: 632-640

KUMARAVELU P, HOOK L, MORRISON AM, URE J, ZHAO S, ZUYEV S, ANSELL J, MEDVINSKY,A (2002) Quantitative developmental anatomy of definitive haematopoietic stem cells/long-term repopulating units (HSC/RUs): role of the aorta-gonadmesonephros (AGM) region and the yolk sac in colonisation of the mouse embryonic liver. Development, 129:4891-4899

MCGRATH KE, KONISKI AD, MALIK J, PALIS J (2003) Circulation is established in a stepwise pattern in the mammalian embryo. Blood, 101: 1669-1676

OTTERSBACH K, DZIERZAK E (2005) The murine placenta contains hematopoietic stem cells within the vascular labyrinth region. Dev Cell, 8: 377-387

ROSSANT J, CROSS JC (2001) Placental development: lessons from mouse mutants. Nat Rev Genet, 2:538548

ZEIGLER BM, SUGIYAMA D, CHEN M, GUO Y, DOWNS KM, SPECK NA (2006) The allantois and chorion, when isolated before circulation or chorioallantoic fusion, have hematopoietic potential. Development, 133: 4183-4192 